\title{
TRACEABILITY SYSTEMS AND TECHNOLOGIES FOR BETTER FOOD SUPPLY CHAIN MANAGEMENT
}

doi: 10.2478/cqpi-2019-0076

Date of submission of the article to the Editor: 21/03/2019

Date of acceptance of the article by the Editor: 06/05/2019

\author{
Samo Kumperščak ${ }^{1}$ \\ Mihael Medved ${ }^{1}$ \\ Melanie Terglav ${ }^{1}$ \\ Aleksandra Wrzalik ${ }^{2}$ - orcid id: 0000-0002-3859-4954 \\ Matevž Obrecht ${ }^{1}$ - orcid id: 0000-0001-8301-7382 \\ 1University of Maribor - Slovenia matevz.obrecht@um.si \\ ${ }^{2}$ Czestochowa University of Technology - Poland aleksandra.rak@wz.pcz.pl
}

\begin{abstract}
Billions of people in the world are at risk of getting unsafe food. There is an urgent need to improve efficiency and effectiveness of food supply chains. The global population is expected to reach at least 9 billion by the year 2050, requiring up to $70 \%$ more food than nowadays and demanding food production and distribution to become much more sustainable. Today, food safety is a worldwide concern due to a number of food safety scandals. As supply chains become more globalized and complex, the ability to track and trace products from fork to farm becomes more difficult but remains equally important. Good traceability may minimize the production and distribution of unsafe or poor quality products. It allows targeting the product affected by a food safety problem, minimizing disruption to trade and any potential public health risks. The objective of this paper is therefore to conduct a comprehensive analysis of traceability methods and technologies in food supply chains.
\end{abstract}

Keywords: food traceability; food supply chain; food safety, RFID

\section{INTRODUCTION}

Traceability is the ability to track any food through all stages of production, processing and distribution. Traceability should mean that movements can be traced one step backwards and one step forward at any point in the supply chain (Millard, Paine, O`Hagen \& Hipkiss, 2015). In practice, traceability systems are record keeping systems that show the path of a particular product from suppliers through intermediate steps to consumers (Pizzuti \& Mirabelli, 2015). As the standard of living improves, concerns over food safety and potential contaminants will continue to be an important health issue (King et al., 2017). Consumers demand quality and safety of products they consume because food as energy and nutrient is necessary to sustain life (Fung, Wang \& Menom, 2018). 
It all starts from the beginning of food production at the farm. Food is considered unsafe when it contains microbiological and chemical contaminants (Dabbene \& Gay, 2011). Many times our main focus is on the end products which might ignored food safety in production phase. The policy should consider safety of primary foods produced through the application of quality management system (Attrey, 2017).

Due to globalization in food trade, food chain integrity does not only include safety but also origin fraud and quality concern (Olsen \& Borit, 2018). Consumers demand verifiable evidence of traceability as an important criterion of food quality and safety (Liu \& Gao, 2016). To tackle these requirements, there is a need for a traceability system giving information on origin, processing, retailing and final destination of foodstuffs (Aung \& Chang, 2014.

In the modern livestock production sector, long distance animal transport is increasing.. Other risk of food such as contamination with radioactive materials disturbs the FSC (Skovgaard, 2005). After release of radioactive from damaged nuclear plants due to earthquake in Japan in 2011, many countries have implemented intensive food control measures concerning their food trade relationship with Japan. In addition to risk to public health, food crises lead to economic crises due to direct and indirect costs of product recall (Bosona \& Gebresenbet, 2013).

This paper therefore focuses on comprehensive review of technologies and methods used for food tracing, with a goal to improve our future food quality and safety.

\section{METHODS}

Paper was created on the basis of a review of scientific databases on a similar topic. Our main focus was tracking-technology systems. We searched articles on three scientific and professional databases: "Science Direct", "Web Of Science" and "Springer link" web sites with keywords: "tracking technology", "food supply chain", "food safety" and "traceability". The determination of relevant articles was first done by reviewing the summaries. Subsequently, we excluded articles that focus not only on traceability within the food supply chains. It was crucial that articles contain different types of traceability and a description of the advantages and disadvantages of a particular traceability method. The emphasis in the search for literature was also on concrete examples of ensuring traceability, because this gave us realistic view of the technology used in practice. Taking into account all the above criteria for finding articles we have studied over fifty scientific papers. The most important information were synthesized and compared. Advantages and disadvantages of using different traceability methods are also investigated and highlighted.

\section{RESULTS}

In the field of food traceability, new technologies are emerging, such as radio frequency identification (RFID) and wireless sensor networks (WSN) and many others. RuizGarcia et al. (2010) describe that most crucial for the success of any traceability system are: (1) compatibility, (2) data standardization and (3) definition of a traceable resource unit.

The most widely used tracking technology in food supply chain is radio frequency identification (RFID). Technology uses radio waves to automatically identify objects. The identification is done by storing a serial number, and perhaps other information, on a microchip that is attached to an antenna. Usually, the retail sector uses bar codes or 
even other forms of labeling (informal non-standardized numbering.). This can lead to major problems in the supply chain, which means that each partner must synchronize his data to comply with the identification applied by the lot producer. (Kelepouris et al., 2007). The main task of RFID technology is to provide members with food distribution information, technical support services and to analyze food consumer behaviors based on the recorded data. The main three actors in the food supply chain are food manufacturers, distribution centers and retailers. Authors define three stages in the implementation of RFID technology, which are: planning and development, pilot testing and implementation. (Hong et al., 2011).

The benefits of using RFID technology are: no line of sight in reading, can read and write tags, higher data rate and larger memory size, reversible tags and it can can read many tags simultaneously (Costa et al., 2013). While weaknesses appear in the need to rely on reader for data collection, a tag cannot initiate communication, no cooperation among the devices, limited capability for environmental sensing and cost still a burden (Aung \& Chang, 2014). RFID technology is widely used in the tracking of live animals, two types of databases are needed for supporting a traceability system. A first database for animals identification is necessary in order to link the single animals to their owners. Other database should include information about animal parameters, animal movements and animal welfare (Pizzuti \& Mirabelli, 2016).

Qian et al., developed a traceability system incorporating 2D barcode and RFID technology for wheat flour mills. Raw materials batches are identified with 14 digits and recorded in the system. In the next stage a processing batch with 16 digits is generated in Stage and also recorded in the system. In the third stage batch code is used to identify the packaged wheat flour, and this code should include information about the raw materials and processing, traceability is now ensured by barcodes (Qian et al., 2012) Barcodes are simple, more economical and offer exact traceability, weaknesses are that reading needs a line of sight, are unreadable if damaged and scanner can only read one label at a time also barcodes cannot collect environmental information (Aung \& Chang, 2014). A QR Code has been selected to identify wheat flour in small packages. Compared to other 2D barcodes, a QR Code was selected for its large capacity, small size and high scanning speed. The company also uses RFID tags affixed to the bin and that is an important step in instituting supply chain traceability (Qian et al., 2012). There is another technology in the field of bar codes that is not in use. Technology is called "Edible Bar codes", marks are applied directly to food, and considered a food additive. Information can be encoded on a microscopic particle.

Feng is describes the method of traceability based on RFID and block-chain technology. The research focuses on two groups of food: fresh fruits \& vegetables, and meats which include pork, mutton, chicken and beef. RFID technology is mostly used in the production, processing, warehousing, distribution and sales, while block-chain technology is a tool for guaranteeing the information which shared and published in this traceability system is reliable and authentic. Block-chain makes the information transparent and open, thus logistics enterprise could implement real-time tracking for the agri-food products (Feng, 2016).

Alfian et al. used a combination of RFID, wireless sensor networks (WSN), and data mining in an e-pedigree food traceability system. A WSN is a technology based on sensor nodes used for sensing, processing, and communication. The sensor nodes collect environmental information, e.g. temperature and humidity, later the data is converted into a digital format and stored in a data base. Today, smartphones are 
widely used all over the world and this technology can be used as gateways to gather sensor data and send it to the server (Alfian et al., 2017). Advantages of WSN are multishop networking, in-network processing, technology can deploy different network topologies, communication is secured among nodes and ability for long reading ranges. While author presents the two weaknesses, tool is not suitable for identification purpose and needs energy saving techniques for continuous sensing (Aung \& Chang, 2014; Tiwari et al., 2015). The integration of RFID and WSN technology allows the final retailer to follow the whole path of the product throughout food supply chain, which assures the retailer that requirements are met throughout product 120 delivery and storage, such as maintaining the required temperature and humidity. Due to various problems (battery power loss, random local interferences)in the distribution of food products sensor data from WSN is often lost. To ensure traceability It is crucial that lost data is recovered and this company ensures it using data mining technology, which can extract knowledge from existing data, and can be utilized to estimate missing values (Alfian et al., 2017). With the advent of new technologies and information systems IOT (Internet of Things) is available in the market. IoT is a novel paradigm that refers to the possibility of endowing everyday objects with the ability to identify and interact with each other to reach cooperation goals. It is a global network infrastructure, based on variety of things (objects)-such as RFID tag, sensors, readers, actuators, mobile phone, NFC etc. Technology is now in use to exchange information about food products (Chen,2015). Quality assurance is crucial to prevent commercial frauds and adulteration cases and that can be prevented by using DNA barcoding. Technology analyses the proteins and/or DNA in food products and ensures traceability. DNA markers are more informative than protein or chemical based methods because DNA better resists industrial processes such as shredding, boiling or pressure cooking. Nowadays system is used as the main tool for plant traceability as well as in the tracking and certification of the raw materials in food industry processes (Galimberti et. al., 2014). Limitations using this method are process of DNA-extraction, sample condition and dependency on a single region of mitochondrial DNA (Jinbo et al., 2011). Advantages are: reliable method, small amount of biological samples needed, applicability for all life stages and differentiation among phenotypically alike species (Dudu et al. 2016). There are several different types of molecular diagnostic methods, such as: conventional pcr, real-time pcr, hrm analysis, capillary electrophoresis, microarrays, next generation sequencing (ngs), dipstick test and loop-mediated isothermal amplification (Madesis et al., 2014). Summary of results are presented on Table 1. 
Advantages and disadvantages of different food supply chain tracking technologies

\begin{tabular}{|c|c|c|}
\hline Technology & Advantages & Disadvantages \\
\hline Bar codes & simple, economical, offer exact traceability, & $\begin{array}{l}\text { reading needs a line of sight, are } \\
\text { unreadable if damaged, scanner } \\
\text { can only read one label at a time, } \\
\text { cannot collect environmental } \\
\text { information }\end{array}$ \\
\hline RFID & $\begin{array}{l}\text { no line of sight needed in reading, can read } \\
\text { and write tags, higher data rate and larger } \\
\text { memory size, reversible tags and it can can } \\
\text { read many tags simultaneously }\end{array}$ & $\begin{array}{l}\text { need to rely on reader for data } \\
\text { collection, a tag cannot initiate } \\
\text { communication, no cooperation } \\
\text { among the devices, limited } \\
\text { capability, cost }\end{array}$ \\
\hline $\begin{array}{l}\text { Wireless } \\
\text { sensor } \\
\text { networks } \\
\text { (WSN) }\end{array}$ & $\begin{array}{l}\text { network setups without fixed infrastructure, } \\
\text { suitable for non-reachable places, } \\
\text { implementation pricing is cheap, small } \\
\text { amount of wiring, easy to accommodate new } \\
\text { devices, flexible to undergo physical } \\
\text { partitions, can be accessed by using a } \\
\text { centralized monitor }\end{array}$ & $\begin{array}{l}\text { reduced security, lower speed as } \\
\text { compared to a wired network, } \\
\text { complicated to configure, easily } \\
\text { troubled by surroundings, unable } \\
\text { to control propagation of waves, } \\
\text { low speed of communication, gets } \\
\text { distracted by various elements, } \\
\text { cost }\end{array}$ \\
\hline DNA barcoding & $\begin{array}{l}\text { very reliable method, small amount of } \\
\text { biological samples needed, applicability for } \\
\text { all life stages, differentiation among } \\
\text { phenotypically alike species }\end{array}$ & $\begin{array}{l}\text { process of DNA-extraction, sample } \\
\text { condition, dependency on a single } \\
\text { region of mitochondrial DNA }\end{array}$ \\
\hline $\begin{array}{l}\text { Tracking using } \\
\text { "block chain" } \\
\text { technolgy }\end{array}$ & $\begin{array}{l}\text { Information are transparent and open, real- } \\
\text { time tracking, better tracking and traceability } \\
\text { management, enhanced credibility of the } \\
\text { agri-food safety information, ability to fight } \\
\text { against fake products }\end{array}$ & $\begin{array}{l}\text { high cost and immaturity of block } \\
\text { chain }\end{array}$ \\
\hline
\end{tabular}

Source: own results

\section{DISCUSSION}

Radio frequency identification (RFID) is often used to track the food supply chain. The main purpose of using RFID is to provide a food supply chain members information about food distribution, technical support services and an analysis of consumer behavior. It is also important to emphasize that tracking in food supply chains should be taken into account throughout the whole life cycle. We can even focus on tracking raw materials from which food are produced. At the end of the life cycle, we can focus on the traceability of waste food, because this is the only way to achieve traceability throughout the entire food chain. RFID technology would increase information visibility, reduce handling and checking, and increase speed when it is integrated in food supply chain (Butcher \& Grant, 2012).

The main players in the food supply chain are food producers, distribution centers and retailers. When introducing RFID technology, three phases are required: design and development, pilot testing and implementation. Agriculture supply chain management 
(ASCM) faces specific challenges such as dependence on weather conditions, involvement of very large number of actors and lack of literacy in the majority of the workforce that lead to requirement of information and communications technologies (ICT) (Mangla, Garg \& Kumar, 2018).

Problems occurring within food supply chains are the nonsynchronization of the use of traceability, which means that they do not use all the members of the same labeling, so it is often impossible to track all the links in the chain. RFID can read multiple tags at once, it has faster data transfer rate and greater memory size. For traceability, simpler and more economical bar codes are also used. Its disadvantages are that its reader can read only one tag at a time, and, in case of damage to the tag, the reader does not detect it and it can not collect environmental information.

QR codes were developed to overcome the information limitation in barcodes. QR stores data along two dimensions and therefore is capable of containing much more information than barcode used in many products such as food and cosmetics (AlKhalifa, 2008).

Combination of RFID and block-chain technology is can also be used for fresh fruit and vegetables and for meat. RFID technology is mainly used in production, processing, storage, distribution and sales, while block-chain technology is used to provide traceability information. The disadvantages of this application are high costs and not the sophistication of block-chain technology.

When reviewing the articles, we were surprised that very high traceability was provided only through bar codes, which are not as effective as any other systems, such as the RFID method. The cause, however is mainly the cost of using other technologies and legislation that is somewhat loose in terms of ensuring traceability. Using RFID technology for tracking, would ensure more effective information on food and its production and decomposition.

\section{CONCLUSION}

This review analyzes various methods and technologies used to track raw materials, semi-products and products in food supply chains. For all methods and technologies advantages and disadvantages were analyzed and discussed. It seems that the most used technologies are currently bar codes and RFID technology. Some of the technologies described are still in the pilot phases and/or in development. Given the rapid advancement of technology and increasing emphasis on food safety, we can expect more methods for food tracking in the future. It would be sensible to repeat the study in several years and compare the results with respect to the advantages and disadvantages of these technologies and new demand on food security and traceability in supply .

\section{REFERENCES}

Kelepouris, T., Pramatari, K., \& Doukidis, G.(2007. RFID- enabled traceability in the food supply chain. Industrial Management \& Data Systems, 107(2), 183200.doi:10.1108/02635570710723804

Hong, I.-H., Dang, J.-F., Tsai, Y.-H., Liu, C.-S., Lee, W.-T., Wang, M.-L., \& Chen, P.-C. 2011. An RFID application in the food supply chain: A case study of convenience stores in Taiwan. Journal of Food Engineering, 106(2), 119126.doi:10.1016/j.jfoodeng.2011.04.014 
Aung, M. M., \& Chang, Y. S. 2014. Traceability in a food supply chain: Safety and quality perspectives. Food Control, 39, 172-184.doi:10.1016/j.foodcont.2013.11.007

Qian, J.-P., Yang, X.-T., Wu, X.-M., Zhao, L., Fan, B.-L., \& Xing, B. 2012. A traceability system incorporating $2 D$ barcode and RFID technology for wheat flour mills. Computers and Electronics in Agriculture, 89, 7685.doi:10.1016/j.compag.2012.08.004

Feng Tian. 2016. An agri-food supply chain traceability system for China based on RFID \& blockchain technology. 2016 13th International Conference on Service Systems and Service Management (ICSSSM).doi:10.1109/icsssm.2016.7538424

Alfian, G., Rhee, J., Ahn, H., Lee, J., Farooq, U., ljaz, M. F., \& Syaekhoni, M. A. 2017. Integration of RFID, wireless sensor networks, and data mining in an e-pedigree food traceability system. Journal of Food Engineering, 212, 6575.doi:10.1016/j.jfoodeng.2017.05.008

Galimberti, A., De Mattia, F., Losa, A., Bruni, I., Federici, S., Casiraghi, M., Labra, M. 2013. DNA barcoding as a new tool for food traceability. Food Research International, 50(1), 55-63.doi:10.1016/j.foodres.2012.09.036

Bosona, T., Gebresenbet, G. 2013. Food traceability as an integral part of logisics management in food and agricultural supply chain. Food Control, 33, 32-48. doi: 10.1016/j.foodcont.2013.02.004

Aung, M., M., Chang, Y., S. 2014. Traceability in a food supply chain: Safety and quality perspectives. Food Control, 39, 172-184. doi: 10.1016/j.foodcont.2013.11.007

Attrey, D., P., 2017. Food safety policies in agriculture and food security with traceability. Food Safety in the 21st Century. Doi: 10.1016/B978-0-12-8017739.00036-4

Fung, F., Wang, H., S., Menon, S., 2019. Food safety in the 21st century. Biomedical Journal, xx, 1-8. doi: 10.1016/j.bj.2018.03.003

King, T., Cole, M., Farber, J., M., Eisenbrand, G., Zabaras, D., Fox, E., M., Hill, J., P. (2017). Food safety for food security: Relationship between global megatrends and developments in food safety. Trends in food science \& technology. Doi: 10.1016/j.tifs.2017.08.014

Ruiz-Garcia, L., Steinberger, G., \& Rothmund, M. 2010. A model and prototype implementation for tracking and tracing agricultural batch products along the food chain. Food Control, 21(2), 112-121. doi:10.1016/j.foodcont.2008.12.00

Madesis, P., Ganopoulos, I., Sakaridis, I., Argiriou, A., \& Tsaftaris, A. 2014. Advances of DNA-based methods for tracing the botanical origin of food products. Food Research International, 60, 163-172.doi:10.1016/j.foodres.2013.10.042

Chen, R.-Y. 2015. Autonomous tracing system for backward design in food supply chain. Food Control, 51, 70-84.doi:10.1016/j.foodcont.2014.11.004

Pizzuti, T., \& Mirabelli, G. 2016. Future Technology in Tracing Animals on the Food Chain. Advances in Food Traceability Techniques and Technologies, 165-190. doi:10.1016/b978-0-08-100310-7.00009-0

Alfian, G., Rhee, J., Ahn, H., Lee, J., Farooq, U., ljaz, M. F., \& Syaekhoni, M. A. 2017. Integration of RFID, wireless sensor networks, and data mining in an e-pedigree food traceability system. Journal of Food Engineering, 212, 6575.doi:10.1016/j.jfoodeng.2017.05.008

Tiwari, P., Saxena, V. Mishra, R. Bhavsar, D. 2015. Wireless Sensor Networks: Introduction, Advantages, Applications and Research Challenges. HCTL Open International Journal of Technology Innovations and Research (IJTIR), 14. 
Jinbo, U., Kato, T., \& Ito, M. 2011. Current progress in DNA barcoding and future implications for entomology. Entomological Science, 14(2), 107124.doi:10.1111/j.1479-8298.2011.00449.x

Dudu, A. Barbălată, T. Popa G. Georgescu S., Costache M. 2016 Advantages and Limitations of DNA Barcoding in Identifying Commercially-Exploited Fish Species. Scientific Papers: Animal Science and Biotechnologies, 49 (1), 91 - 95

Costa, C., Antonucci, F., Pallotino, F., Aguzzi, J., Sarria, D. \& Menesatti, P. 2013. A Review on Agri-food Supply Chain Traceability by Means of RFID Technology. Food and Bioprocess Technology, 2, 353-366. doi: 10.1007/s11947-012-0958-7

Butcher, T. \& Grant, D. B. 2012. Identifying Supply Chain Value Using RFID-Enabled Distributed Decision-Making for Food Quality and Assurance. Decision-Making for Supply Chain Integration, 89-103. doi: 10.1007/978-1-4471-4033-7_5

Luthra, S. Mangla, S. K., Garg, D. \& Kumar, A. 2018. Internet of Things (loT) in Agriculture Supply Chain Management: A Developing Country Perspective. Emerging Markets from a Multidisciplinary Perspective, 209-220. doi: 10.1007/9783-319-75013-2_16

Al-Khalifa, H. S. 2008. Utilizing QR Code and Mobile Phones for Blinds and Visually Impaired People. Computers Helping People with Special Needs, 1065-1069. doi: 10.1007/978-3-540-70540-6_159

Olsen, P., Borit, M. 2018. The components of a food traceability system. Trends in Food Science \& Technology. 77, 143-149. doi: 10.1016/j.tifs.2018.05.004

Millard, P., Paine, S., O`Hagan, S., Hipkiss, J., 2015. Traceability of allergenic foods in the food chain. Handbook of Food Allergen Detection and Control, 19-40. doi: 10.1533/9781782420217.1.19.

Pizzuti, T., Mirabelli, G. 201). The Global Track\&Trace System for food: General framework and functioning principles. Journal of Food Engineering, 159, 16-35. doi: 10.1016/j.jfoodeng.2015.03.001.

Liu, Y., Gao, H. 2016. Chapter 12 - Development and Applications of Mobile Farming Information System for Food Traceability in Health Management. Applied Computing in Medicine and Health, 244-268. doi: 10.1016/B978-0-12-8034682.00012-6.

Dabbene, F., Gay, P., 2011. Food traceability systems: Performance evaluation and optimization. Computers and Electronics in Agriculture, 75, 139-146. doi: 10.1016/j.compag.2010.10.009

Skovgaard, N., 2005. Bioterrorism and Food Safety. International Journal of food Microbiology, 105, 93. doi: 10.1016/j.jfoodmicro.2005.06.004. 